\title{
Implementasi Hazard Analysis and Critical Control Point (HACCP) dalam Penyimpanan Bahan Baku Makanan di Hotel Discovery Kartika Plaza Hotel
}

\author{
Kadek Dwi Arisandi, Trianasari, Putu Gede Parma \\ Undiksha
}

\begin{abstract}
Abstrak
Penelitian ini bertujuan untuk mengetahui (1) Penerapan sistem hazard analysis and critical control point (HACCP) dalam penyimpanan bahan baku makanan di main kitchen Discovery Kartika Plaza Hotel (2) Kendala apa saja yang terjadi di main kitchen (3) Bagaimana upaya chef de partie dalam menangani masalah yang ada. Penelitian ini menggunakan rancangan deskriptif kualitatif yang memaparkan data yang telah terkumpul melalui observasi dan wawancara serta dokumentasi yang telah dilakukan secara langsung kepada chef de partie. Hasil dari penelitian ini menunjukan bahwa Discovery Kartika Plaza Hotel memiliki prosedur penyimpanan yang sesuai dengan sistem Hazard Analysis and Critical Control Point (HACCP). Dalam melaksanakan kegiatan-kegiatan di main kitchen Discovery Kartika Plaza Hotel masih banyak mengalami permasalahan. Untuk mengatasi permasalahan yang ada chef de partie di main kitchen mempunyai upaya-upaya untuk mengatasi permasalahan yang ada.
\end{abstract}

Kata Kunci: chef de partie, hazard analysis and critical control point (haccp), main kitchen, penyimpanan bahan makanan.

\begin{abstract}
This study aimed to understand (1) the application of hazard analysis and critical control point (HACCP) systems in the storage of food raw materials in the kitchen of Discovery Kartika Plaza Hotel (2) The kinds obstacles occur in the kitchen (3) How chef de partie attempts to deal with existing problems. This study used a descriptive qualitative design that describes the data that have been collected through observation, interviews and documentation of to the hotel staff. The results of this study indicate that Discovery Kartika Plaza Hotel has a storage procedure that is in accordance with the Hazard Analysis and Critical Control Point (HACCP) system. In carrying kitchen activities, Discovery Kartika Plaza Hotel still faces many problems. To overcome the problems chef de partie have several strategies efforts to overcome them.
\end{abstract}

Key world: chef de partie, hazard analysis and critical control point (haccp), main kitchen, strorage of food ingredients

\section{Pendahuluan}

Perkembangan dunia pariwisata yang begitu cepat akan sangat mempengaruhi perekonomian masyarakat, usaha-usaha di sektor pariwisata seperti pelayanan akomodasi restoran, tempat wisata keluarga, tempat wisata budaya dan usaha perhotelan tentunya. Hotel merupakan akomodasi yang sangat penting bagi dunia pariwisata dikarenakan pada era modern ini perjalanan wisata yang jauh sudah sangat mungkin untuk dilakukan, maka dari itu 
wisatawan sangatlah membutuhkan jasa penginapan seperti hotel. Maraknya usaha hotel membuat para pengusaha bersaing untuk memberikan pelayanan yang maksimal bagi para wisatawan. Pelayanan seperti kenyamanan, keramahan sampai pada kualitas produk sangatlah berpengaruh terhadap kepuasan tamu.

Food Production Department adalah Departemen ini bertanggung jawab atas kualitas pelayanan di bidang produk makanan. Seperti di Discovery Kartika Plaza Hotel, food production department sangat memperhatikan kualitas dan keamanan produk atau makanan yang akan disajikan kepada tamu. Kualitas dan keamanan suatu produk makanan tidak terlepas dari prosedur-prosedur dan aturan-aturan pengolahan makanan, aturan dan prosedur tersebut diterapkan dalam suatu sistem yang di sebut Hazard Analysis and Critical Control Point (HACCP). HACCP bertujuan untuk mengidentifikasi dan pengendalian bahaya (hazard) mulai dari penerimaan bahan, penyimpanan, proses produksi hingga penyajian kepada tamu. Keamanan pangan merupakan hal yang sangat penting untuk menghindari terjadinya efek samping yang ditimbulkan dari kontaminasi, penyalahgunaan dan keracunan pada makanan. Ada beberapa hal yang menyebabkan menurunnya kualitas pangan, diantaranya adalah penyimpanan bahan makanan yang kurang tepat, pengolahan dan penyajian yang tidak sesuai dengan prosedur-prosedur yang berlaku. Kendala-kendala yang sering terjadi pada saat melakukan observasi di hotel yang berkaitan dengan Hazard Analysis and Critical Control Point (HACCP) adalah makanan yang berada di buffet menjadi rusak atau cepat basi setelah beberapa jam disajikan dan bahan makanan mentah maupun setengah matang tidak bertahan lama di dalam penyimpanan.

Dari latar belakang tersebut maka penulis dapat merumuskan masalah yaitu: (1) Bagaimana penerapan sistem hazard analysis and critical control point (HACCP) dalam penyimpanan bahan baku di main kitchen discovery kartika plaza hotel ? (2) Apa saja permasalahan di main kitchen discovery kartika plaza hotel ? (3) bagaimana upaya chef de partie dalam menangani permasalahan di main kitchen?

\section{Kajian Pustaka}

\subsection{Sistem Hazard Analysis and Critical Control Point (HACCP)}


Menurut Muhandri dan Kadarisman, (2008) HACCP merupakan suatu sistem yang digunakan untuk mengkategorikan bahaya dan menentukan sistem pengendalian yang memfokuskan pada pencegahan. Kunci utama HACCP adalah antisipasi bahaya dan identifikasi titik pengawasan yang mengutamakan kepada tindakan pencegahan dari pada mengandalkan kepada pengujian produk akhir. Sistem HACCP bukan merupakan sistem jaminan keamanan pangan yang zero-risk atau tanpa resiko, tetapi dirancang untuk meminimumkan resiko bahaya keamanan pangan. HACCP dapat diterapkan dalam rantai produksi pangan mulai dari produsen utama bahan baku pangan (pertanian), penanganan, pengolahan, distribusi, pemasaran hingga sampai kepada pengguna akhir. Karena HACCP dikenal sebagai sistem keamanan pangan yang efektif, maka dengan menerapkan HACCP secara konsekuen maka perusahaan jaminan pangan akan dapat memberikan kepercayaan pada pelanggan terhadap jaminan keamanan yang telah dilakukan, dan akan memberikan kesan yang baik bahwa industri pangan yang bersangkutan memenuhi komitmen yang kuat dan profesional dalam menjamin keamanan pangan.

\subsection{Penyimpanan Bahan Makanan}

Penyimpanan bahan makanan merupakan satu dari 6 prinsip higiene dan sanitasi makanan. Penyimpanan bahan makanan yang tidak baik, terutama dalam jumlah yang banyak (untuk katering dan jasa boga) dapat menyebabkan kerusakan bahan makanan tersebut. Adapun tata cara penyimpanan bahan makanan yang baik menurut sitem HACCP dalam Anonim (2010) adalah suhu penyimpanan yang baik dan tata cara menyimpan.

Bahan makanan di dalam sebuah hotel merupakan investasi yang sangat besar. Jika sebuah hotel tidak dapat menjaga ketersediaan bahan makanan, maka besar kemungkinan hotel tersebut akan mengalami kerugian. Penyimpanan bahan makanan (food storage) di dalam sebuah hotel merupakan salah satu cara untuk menjaga ketersediaan bahan makanan agar tidak kekurangan pada saat dibutuhkan. Beberapa hotel yang kurang memperhatikan proses penyimpanan bahan makan pada akhirnya akan mengalami kerusakan bahan makanan, kerugian, dan bahkan berakibat pada kebangkrutan.

\subsection{Pengendalian suhu dan kelembapan}

Setiap bahan makanan harus mendapatkan perlakuan yang berbedabeda, terutama saat disimpan di dalam gudang. Bahan makanan harus disimpan 
di gudang dengan suhu dan kelembaban yang berbeda, karena jika tidak, bahan makanan akan mengalami kerusakan dan hal ini dapat merugikan pihak restoran. Suhu dan kelembaban gudang juga harus diperhatikan dengan baik. Food Controller dan petugas gudang harus memeriksa alat pengukur suhu secara berkala untuk memastikan suhu dapat terpelihara dan terjaga dengan baik.

\subsection{Penempatan dan pengaturan bahan makanan}

Setiap bahan makanan yang disimpan harus diletakkan secara terpisah menurut jenisnya, dalam wadah (container) masing-masing. Hal ini bertujuan untuk menghindari terjadinya kontaminasi bahan makanan dan juga kerusakan. Wadah penyimpanan dapat berupa stainless-steel, wadah plastik, atau wadah tertutup lainnya.

Penyimpanan di dalam lemari es (chiller):

- Bahan mentah harus terpisah dari makanan siap santap

- Makanan yang berbau tajam harus ditutup dengan plastic wrap yang rapat dan dipisahkan dari makanan lain, atau di dalam lemari yang berbeda

- Makanan yang di simpan sebaiknya di gunakan tidak lebih dari 2 atau 3 hari

- Lemari tidak boleh terlalu sering dibuka, karena dapat mempengaruhi suhu dan berisiko terjadi kerusakan bahan makanan.

Penyimpanan makanan kering:

- Suhu cukup sejuk, udara kering dengan ventilasi yang baik

- Ruangan bersih, kering, lantai, dan dinding tidak lembab

- Rak-rak berjarak minimal $15 \mathrm{~cm}$ dari dinding lantai dan $60 \mathrm{~cm}$ dari langitlangit

- Rak mudah dibersihkan dan dipindahkan

- Penempatan dan pengambilan barang diatur dengan sistem FIFO (first in first out) artinya makanan yang masuk terlebih dahulu harus dikeluarkan terlebih dahulu.

\subsection{Peranan Hazard Analysis and Critical Control Point (HACCP) terhadap Penyajian Makanan}

Penyajian makanan adalah tahap akhir dari semua proses di kitchen, di sinilah makanan akan ditaruh di atas alat saji dan disajikan kepada tamu. Dalam 
penyajian makanan perlu diperhatikan hal-hal penting, seperti mengenai keamanan tempat penyajian, kebersihan dan kelayakannya berikut adalah aspek-aspek yang diperhatikan dalam penyajian di Hotel Discovery Kartika Plaza: 1. Kebersihan Alat Saji. Hal yang paling penting dalam penyajian adalah kebersihan alat saji, hal ini dikarenakan makanan akan berinteraksi langsung dengan alat penyajian. 2.Penyimpanan alat saji Alat yang saji harus disimpan di tempat yang kering dan tidak lembab. Hal ini untuk mencegah timbulnya jamur dan parasit lain yang dapat menyebabkan kontaminasi terhadap makanan yang akan disajikan. 3. Kelayakan alat saji. Alat saji yang digunakan untuk menyajikan makanan haruslah layak, maksudnya adalah sebuah alat saji seperti, mangkuk, piring dan sendok tidak boleh memiliki kecacatan dalam bentuk fisiknya. Seperti yang diterapkan oleh Hotel Discovery Kartika Plaza meliputi:

1. Penyajian dalam bentuk buffet

Buffet atau biasa disebut dengan prasmanan adalah cara penyajian di mana makanan yang disajikan berada di tempat yang memuat cukup banyak makanan dan para tamu akan mengambil makanan sendiri.

2. Penyajian dalam bentuk Ala Carte

Ala Carte adalah suatu susunan menu, di mana makanan yang dicantumkan pada daftar makanan tersebut disertai dengan harga tersendiri.

3. Penyajian dalam bentuk Room Service atau layanan kamar Layanan kamar atau Room Service hampir sama dengan Ala Carte, hanya saja langkah-langkah penyajiannya berbeda. Jika Ala Carte biasanya tamu memesan di restoran hotel akan tetapi room service dipesan dari kamar hotel. Yang menjadi pembeda adalah proses pelayanannya dikarenakan makanan yang akan disajikan haruslah dibawa ke kamar yang pada dasarnya jarak kamar dari kitchen lumayan memakan waktu.

\subsection{Penelitian Terdahulu}

\begin{tabular}{|c|c|c|c|}
\hline No & Nama Peneliti & Judul Penelitian & Hasil Penelitian \\
\hline 1 & $\begin{array}{l}\text { Widianto dan } \\
\text { Mayasari (2018) }\end{array}$ & $\begin{array}{l}\text { Penerapan HACCP di } \\
\text { Main Kitchen Hotel Ibis } \\
\text { Styles Yogyakarta }\end{array}$ & $\begin{array}{l}\text { Prosedur } \\
\text { Sistem HACCP telah } \\
\text { dimiliki oleh Hotel lbis } \\
\text { Styles Yogyakarta }\end{array}$ \\
\hline 2 & $\begin{array}{l}\text { Prasetyanto dan } \\
\text { Ratri ( 2018) }\end{array}$ & $\begin{array}{r}\text { Penerapan } \\
\text { pada }\end{array}$ & $\begin{array}{l}\text { Bagan alir yang disusun } \\
\text { telah mencakup dari }\end{array}$ \\
\hline
\end{tabular}




\begin{tabular}{|c|c|c|c|}
\hline & & $\begin{array}{l}\text { Pengolahan Makanan } \\
\text { di Mainkitchen Hyatt } \\
\text { Regency Yogyakarta }\end{array}$ & $\begin{array}{l}\text { semua tahapan mulai dari } \\
\text { penerimaan makanan dari } \\
\text { vendor, sampai pada } \\
\text { proses penyajian } \\
\text { makanan pada tamu. } \\
\text { Hyatt Regency Yogyakarta } \\
\text { memiliki dua bagan alir } \\
\text { dalam HACCP plan yaitu } \\
\text { Hot Process dan Cool } \\
\text { Process. }\end{array}$ \\
\hline 3 & Bestari (2018) & $\begin{array}{l}\text { Sanitasi dan Personal } \\
\text { Hygiene dalam Kitchen } \\
\text { Hotel Louis Kienne } \\
\text { Pandanaran Semarang }\end{array}$ & $\begin{array}{l}\text { Sanitasi dan personal } \\
\text { hygiene dalam dapur } \\
\text { Hotel Louis Kienne } \\
\text { Pandanaran Semarang } \\
\text { masih belum sepenuhnya } \\
\text { memenuhi standar yang } \\
\text { tertulis pada peraturan } \\
\text { menteri kesehatan } \\
\text { republik indonesia. }\end{array}$ \\
\hline 4 & Intanasari (2018) & $\begin{array}{l}\text { Higenitas dan Sanitasi } \\
\text { yang Diterapkan di } \\
\text { Kitchen Hotel Louis } \\
\text { Kienne Simpang Lima } \\
\text { Semarang }\end{array}$ & $\begin{array}{l}\text { Hotel Louis Simpang Lima } \\
\text { juga mempunyai standar } \\
\text { higienitas dan sanitasi } \\
\text { dalam pengolahan } \\
\text { makanannya, namun } \\
\text { penerapannya masih } \\
\text { belum dilaksanakan } \\
\text { dengan baik oleh para } \\
\text { pekerja dapur. }\end{array}$ \\
\hline 5 & Widya (2014) & 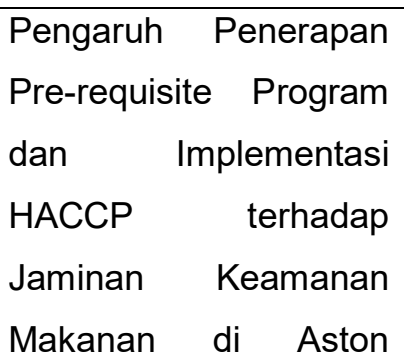 & $\begin{array}{l}\text { Penerapan Pre-Requisite } \\
\text { dan Implementasi HACCP } \\
\text { yang masih belum } \\
\text { berjalan maksimal di } \\
\text { Aston Braga \& Residence. }\end{array}$ \\
\hline
\end{tabular}




\begin{tabular}{|l|l|l|l|}
\hline & $\begin{array}{l}\text { Braga Hotel \& } \\
\text { Residence }\end{array}$ & \\
\hline
\end{tabular}

\section{Metode Penelitian}

Penelitian ini menggunakan rancangan deskriptif kualitatif yang memaparkan data yang telah terkumpul melalui observasi dan wawancara serta dokumentasi yang dilakukan secara langsung kepada pihak hotel terkait data yang akan diperlukan pada penelitian ini.

\subsection{Lokasi Penelitian}

Penelitian ini dilaksanakan di Discovery Kartika Plaza Hotel selama 6 bulan yang berlokasi di Jln Kartika Plaza, Kuta, Badung Bali dengan kode pos 80361. Penelitian ini dilakukan di bagian food production.

\subsection{Jenis Data}

Jenis data yang akan diambil adalah data primer dan sekunder. Data primer adalah data yang diambil langsung di lokasi penelitian. Adapun data primer yang diambil peneliti antara lain data mengenai sistem HACCP, observasi langsung kondisi penyimpanan bahan baku di Chiller. Data sekunder adalah data yang diambil dari data yang telah dipublikasi seperti literatur, artikel, jurnal serta situs di internet yang memperkuat literatur review pada bab 2 serta argumen untuk dibagian pembahasan pada bab 4.

\subsection{Subjek dan Objek Penelitian}

Subjek pada penelitian ini adalah manager higiene sanitasi dan chef de partie main kitchen di Discovery Kartika Plaza Hotel Objek pada penelitian ini adalah penerapan sistem HACCP dalam penyimpanan bahan baku makanan yang ada di kitchen.

\subsection{Teknik pengumpulan data}

Teknik pengumpulan informasi berupa data-data yang dibutuhkan untuk menganalisis objek penelitian ini adalah :

1. Observasi

Teknik pengumpulan data yang dilakukan secara langsung pada objek penelitian. Penulis mengamati secara langsung segala kegiatan yang 
berkaitan dengan Hazard Analysis and Critical Control Point (HACCP) di Kartika Plaza Hotel, terutama pada penyimpanan bahan makanan di main kitchen yang sesuai dengan rinsip HACCP.

2. Wawancara (Interview)

Mahadewi dan Utama (2012) wawancara adalah "proses tanya-jawab dalam penelitian yang berlangsung secara lisan". Penulis melakukan wawancara tanya jawab langsung kepada juru masak atau chef dan staf main kitchen di Kartika Plaza Hotel. Metode wawancara terlampir.

3. Dokumentasi (Documentation)

Mahadewi dan Utama (2012) dokumentasi adalah "pengambilan data yang diperoleh melalui dokumen-dokumen". Penulis mendokumentasikan hal-hal yang dianggap perlu dan dapat menjadi bukti penelitian. Seperti foto keadaan chiller,table preaparation, tabel pengecekekan suhu pada chiller.

\subsection{Teknik Analisis Data}

Teknik analisis data yang digunakan untuk penelitian ini adalah deskriptif kualitatif yaitu menguraikan dan memaparkan data yang telah diperoleh dari tempat penelitian yang berhubungan dengan permasalahan. Tujuan metode ini adalah menggambarkan secara sistematis terhadap fenomena yang terjadi.

4. Hasil Penelitian dan Pembahasan

4.1. Penerapan Hazard Analysis and Critical Control Point (HACCP) dalam Penyimpanan Bahan Baku di Main Kitchen Discovery Kartika Plaza Hotel 
Penyimpanan bahan makanan merupakan salah satu dari 8 CCP (critical control point) yang ada dimana dalam CCP (critical control point) 3 tercantum tentang chill storage atau tempat penyimpanan bahan makanan, penyimpanan bahan makanan yang tidak baik terutama dalam jumlah yang banyak dapat menyebabkan kerusakan bahan makanan tersebut. Berdasarkan hasil penelitian yang sudah peneliti lakukan penerapan sistem HACCP terhadap penyimpanan bahan baku yang diterapkan di main kitchen discovery kartika plaza hotel telah dilaksanakan dengan baik dan sesuai standar, sehingga dapat dikatakan bahwa seluruh kegiatan penyimpanan bahan makanan di main kitchen discovery kartika plaza hotel telah mampu menjamin keamanan pangan.

Adapun tata cara penyimpanan bahan makanan yang baik menurut sitem HACCP dalam Anonim (2010) adalah suhu penyimpanan yang baik dan tata cara menyimpan. Bahan makanan di dalam sebuah hotel merupakan investasi yang sangat besar. Jika sebuah hotel tidak dapat menjaga ketersediaan bahan makanan, maka besar kemungkinan hotel tersebut akan mengalami kerugian. Penyimpanan bahan makanan (food storage) di dalam sebuah hotel merupakan salah satu cara untuk menjaga ketersediaan bahan makanan agar tidak kekurangan pada saat dibutuhkan. Penyimpanan bahan makanan di hotel harus sangat diperhatikan karena bahan makanan pada dasarnya memiliki sifat mudah rusak, apalagi jika disimpan di dalam gudang yang tidak bersih, tidak teratur, dan juga tidak dijaga dengan baik.

Beberapa hotel yang kurang memperhatikan proses penyimpanan bahan makan pada akhirnya akan mengalami kerusakan bahan makanan, kerugian, dan bahkan berakibat pada kebangkrutan. Oleh karena itu, pihak restoran harus banyak memberikan perhatian dalam proses penyimpanan dan pemakaian bahan makanan, salah satunya dengan menyediakan gudang penyimpanan bahan makanan (food store). Dalam proses penyimpanan bahan makanan, ada beberapa faktor yang harus diperhatikan, di antaranya:

\subsection{Pengendalian suhu dan kelembapan}

Setiap bahan makanan harus mendapatkan perlakuan yang berbeda-beda, terutama saat disimpan di dalam gudang. Bahan makanan harus disimpan di gudang dengan suhu dan kelembaban yang berbeda, karena jika tidak, bahan makanan akan mengalami kerusakan dan hal ini dapat merugikan pihak restoran. Suhu dan kelembaban gudang juga harus diperhatikan dengan baik. Food 
Controller dan petugas gudang harus memeriksa alat pengukur suhu secara berkala untuk memastikan suhu dapat terpelihara dan terjaga dengan baik.

- Dry storage merupakan gudang untuk menyimpan bahan makanan dalam kemasan, makanan dalam kaleng, plastik, kardus, botol, atau bahan makanan kering lainnya. Dry storage biasanya dipertahankan pada suhu antara $18^{\circ} \mathrm{C}-38^{\circ} \mathrm{C}\left(50^{\circ} \mathrm{F}-70^{\circ} \mathrm{F}\right)$. Hal ini bertujuan agar gudang terhindar dari serangan hama dan serangga.

- Cold storage merupakan gudang penyimpanan yang tersedia untuk bahan makanan yang mudah rusak (perishable) dan dairy products, seperti telur, mentega, daging, dan susu. Bahan makanan akan terjaga jika disimpan pada suhu antara $-1^{\circ} \mathrm{C}$ sampai $-7^{\circ} \mathrm{C}\left(30^{\circ} \mathrm{F}-45^{\circ} \mathrm{F}\right)$. Selain itu, di dalam cold storage, bahan makanan juga harus diletakkan pada rak yang terpisah, karena jika disatukan, dapat menyebabkan terjadinya kontaminasi yang berakibat pada kerusakan bahan makanan.

- Freezer storage merupakan gudang penyimpanan dengan suhu $-18^{\circ} \mathrm{C}$ $\left(0^{\circ} \mathrm{F}\right)$ atau lebih rendah. Freezer digunakan untuk menyimpan berbagai jenis daging dan frozenfood, dan es krim yang dikonsumsi dalam jangka waktu yang cukup lama.

\subsection{Penempatan dan pengaturan bahan makanan}

Setiap bahan makanan yang disimpan harus diletakkan secara terpisah menurut jenisnya, dalam wadah (container) masing-masing. Hal ini bertujuan untuk menghindari terjadinya kontaminasi bahan makanan dan juga kerusakan. Wadah penyimpanan dapat berupa stainless-steel, wadah plastik, atau wadah tertutup lainnya. Bahan makanan di simpan di dalam gudang penyimpanan sedemikian hingga terjadi sirkulasi udara dengan baik. Dalam hal ini, pihak restoran harus mengatur gudang agar bahan-bahan tersimpan dengan teratur dan tidak penuh agar suhu dan kelembaban gudang dapat terjaga.

Penyimpanan didalam lemari es (chiller):

- Bahan mentah harus terpisah dari makanan siap santap 
- Makanan yang berbau tajam harus ditutup dengan plastic wrap yang rapat dan dipisahkan dari makanan lain, atau di dalam lemari yang berbeda

- Makanan yang disimpan sebaiknya di gunakan tidak lebih dari 2 atau 3 hari

- Lemari tidak boleh terlalu sering dibuka, karena dapat mempengaruhi suhu dan berisiko terjadi kerusakan bahan makanan.

Penyimpanan makanan kering:

- Suhu cukup sejuk, udara kering dengan ventilasi yang baik

- Ruangan bersih, kering, lantai, dan dinding tidak lembab

- Rak-rak berjarak minimal $15 \mathrm{~cm}$ dari dinding lantai dan $60 \mathrm{~cm}$ dari langitlangit

- Rak mudah dibersihkan dan dipindahkan

- Penempatan dan pengambilan barang diatur dengan sistem FIFO (first in first out) artinya makanan yang masuk terlebih dahulu harus dikeluarkan terlebih dahulu.

Penerapan sistem HACCP dalam penyimpanan bahan baku makanan yang dilakukan di main kitchen Hotel Discovery Kartika Plaza sudah sesuai dengan memaparan diatas bisa kita lihat dari hasil penelitian yang sudah peneliti lakukan. Adapun proses penyimpanan bahan makanan yang dilakukan sebagai berikut :

1) Penerimaan barang dari Purchasing Semua bahan baku makanan yang dibutuhkan oleh hotel, khususnya oleh main kitchen akan melalui bagian purchasing terlebih dahulu. Purchasing akan mengecek bahan baku makanan yang sudah dipesan dari supplier sesuai dengan standar perusahaan atau tidak, apabila bahan makanan atau barang yang dipesan tidak sesuai dengan yang dipesan atau tidak sesuai dengan standar perusahaan bagian purchasing akan mengembalikan atau menolak barang tersebut kepada supplier. Jika sudah memenuhi standar persyaratan, pihak purchasing akan menginformasikan kepada bagian main kitchen jika bahan makanan yang dipesan sudah datang sesuai dengan yang di butuhkan. Pihak main kitchen akan mengambil bahan makanan yang sudah dipesan dan harus menyimpan bahan tersebut 
dengan baik dan benar agar bahan makanan tersebut tidak mudah rusak. Sebelum disimpan bahan makanan seperti sayuran dan buah harus dibersihkan terlebih dahulu dan dipisahkan sesuai dengan jenisnya. Setelah dibersihkan dan dipisahkan sesuai jenisnya baru dimasukkan ke dalam almari pendingin atau chiller. Bahan makanan seperti daging, ikan, unggas dan seafood juga dipisahkan sesuai dengan jenisnya, kemudian dimasukkan ke dalam box penyimpanan yang bersih. Setelah dimasukkan ke dalam box yang bersih tulis tanggal penyimpanan di luar box agar semua karyawan mengetahui bahan makanan mana yang harus digunakan terlebih dahulu untuk menghindari kerusakan bahan makanan karena terlalu lama dalam penyimpanan.

2) 2. Suhu penyimpanan Setiap bahan baku makanan memiliki spesifikasi penyimpanan yang berbeda, tergantung dari jenis, jumlah, ukuran dan tempat penyimpanannya. Beberapa bahan baku makanan dapat di kelompokkan menjadi: a.Bahan baku makanan jenis daging, unggas ikan atau seafood Bahan makanan ini termasuk dalam penyimpanan bahan makanan cold food, biasa disimpan dalam suhu di bawah $40^{\circ} \mathrm{F}$. Bahan makanan yang disimpan dengan suhu di bawah $40^{\circ} \mathrm{F}$ masa penyimpanan bertahan selama 7 hari sejak penyimpanan. Dalam almari penyimpanan atau chiller terdapat temperature control di mana setiap pergantian shift staff kitchen harus mengkontrol suhu temperature penyimpanan tersebut. Karena apabila suhu melebihi batas minimal penyimpanan bahan makanan akan terkontaminasi oleh bakteri-bakteri yang bisa menyebabkan kerusakan bahan makanan. b.Bahan baku sayuran dan buah-buahan dalam penyimpanan sayur dan buah harus di pisahkan untuk mencegah proses pembusukan. Bahan baku sayuran dan buahbuahan juga di pisahkan sesuai dengan jenisnya. Bahan baku seperti brokoli, apel, wortel, tomat, kol dan sejenisnya memerlukan suhu penyimpanan sekitar $40-50^{\circ} \mathrm{F}$. Bahan kering seperti bawang merah dan bawang putih memerlukan suhu penyimpanan sekitar $32-39^{\circ} \mathrm{F}$. Rata rata penyimpanan bahan makanan ini adalah 1 minggu. c.Bahan makanan jenis telur dan susu Penyimpanan bahan makanan untuk satu minggu suhu penyimpanan harus di bawah $-5^{\circ} \mathrm{C}$ toleransi maksimal suhu $8^{\circ} \mathrm{C}$ d.Bahan makanan kering seperti tepung, biji-bijian di simpan di dalam dry store dengan suhu ruangan rata-rata $25^{\circ} \mathrm{C}$. 
3) Penyimpanan bahan makanan kering

a. Dry store harus benar dalam keadaan kering

b. Dry store harus memiliki penerangan yang cukup

c. Dry store harus memiliki ventilasi udara yang cukup

d. Rak penyimpanan harus mudah di jangkau

e. Penempatan dan pengambilan barang diatur dengan sistem FIFO (First In First Out)

f. Membuat check list daftar stock barang agar memudahkan dalam pengecekan persediaan barang.

\subsection{Permasalahan di Main Kitchen Discovery Kartika Plaza Hotel}

Berdasarkan hasil penelitian yang sudah dilakukan dapat diketahui bahwa masih banyak terdapat permasalahan yang bisa ditemui di main kitchen Discovery Kartika Plaza Hotel salah satunya adalah kelalaian yang sering terjadi dalam penyimpanan atau FIFO (first in first out) yang tidak dijalankan sesuai dengan prosedur, hal ini juga menjadi masalah, misalnya saat menyimpan bahan makanan. Bahan makanan yang terlebih dahulu datang atau bahan makanan yang lama tidak boleh berada di bawah seharusnya berada di atas atau di depan bahan makanan baru. Hal ini mencegah terjadinya bahan makanan kadaluwarsa atau busuk karena penyimpanan yang terlalu lama. Kelalaian yang sering terjadi dalam penyimpanan bahan makanan atau penerapan sistem (first in first out) FIFO disebabkan karena kurangnya kesadaran staf main kitchen terhadap bahayanya kelalaian dalam menjalankan prosedur. Sebaiknya mengatasi hal tersebut adalah Chef De Partie, di mana Chef de partie bertugas untuk menambah wawasan melalui traning HACCP yang akan diberikan kepada setiap karyawan atau staf yang dirasa kurang paham tentang pentingnya pengendalian bahaya yang sesuai dengan prinsip HACCP.

Main kitchen juga mengalami kekurangan bahan mentah makanan karena tempat penyimpanan bahan makanan yang jauh dari areal penyajian, kekuranan bahan makanan sering terjadi terutama pada saat breakfast. Kebutuhan bahan mentah makanan yang tidak sesuai dengan ketersediaan yang ada dipenyimpanan bahan makanan dekat penyajian dapat menghambat penyediaan makanan. Selain itu chef de partie juga lalai dalam menjalankan 
tugas untuk mengecek persediaan bahan makanan, terkadang chef de partie juga lupa mengecek persediaan yang sudah disediakan oleh commis yang bekerja pada malam hari sehingga dapat menyebabkan penurunan standar pelayanan. Main kitchen juga menangani makanan yang ada dibeberapa outlet restoran ini juga merupakan salah satu kendala yang ada di main kitchen karena banyaknya makanan yang ditangani dibeberapa outlet restoran menyebabkan penurunan taste pada saat penyajian.

\subsection{Upaya Chef De Partie Mengatasi Permasalahan di Main Kitchen Discovery Kartika Plaza Hotel}

Salah satu masalah yang sering terjadi adalah tempat penyimpanan bahan baku makanan yang ada diareal penyajian makanan belum maksimal, dilihat dari kurangnya bahan pokok pada saat akan membuat suatu makanan yang berdampak pada kualitas makanan itu sendiri. Hal ini disebabkan karena kurangnya ketersediaan tempat penyimpanan bahan makanan di areal penyajian makanan. Hal ini juga berpengaruh terhadap penyajiaan makanan yang dilakukan pada saat breakfast atau membuat orderan karena penyediaan tempat penyimpanan bahan makanan yang ada diareal penyajian makanan sangat terbatas. Adapun cara untuk mengatasi permasalah yang ada di main kitchen adalah meminimalisir penggunaan bahan makanan agar dapat disimpan di dekat area penyajain. Chef de partie mempunyai tugas mengarahkan setiap staff di main kitchen untuk melakukan preaperation sebelum memulai menjalankan tugasnya di masing-masing section hal ini disebabkan karena tempat penyimpanan bahan makanan atau chiller jauh dari areal penyajian makanan.

Adapun masalah lainnya yang ada di main kitchen Discovery Kartika Plaza Hotel adalah kelalaian yang sering terjadi dalam penyimpanan atau FIFO (first in first out) yang tidak dijalankan sesuai dengan prosedur, hal ini juga menjadi masalah, misalnya saat menyimpan bahan makanan. Bahan makanan yang terlebih dahulu datang atau bahan makanan yang lama tidak boleh berada di bawah seharusnya berada di atas atau di depan bahan makanan baru. Hal ini mencegah terjadinya bahan makanan kadaluwarsa atau busuk karena penyimpanan yang terlalu lama. Kelalaian yang sering terjadi dalam penyimpanan bahan makanan atau penerapan sistem FIFO (first in first out) disebabkan karena kurangnya kesadaran staff main kitchen terhadap bahayanya 
kelalaian dalam menjalankan prosedur. Sebaiknya dalam mengatasi hal tersebut Chef de partie mempunyai tugas untuk menambah wawasan melalui traning HACCP yang akan diberikan kepada setiap karyawan atau staf yang dirasa kurang paham tentang pentingnya pengendalian bahaya yang sesuai dengan prinsip $H A C C P$.

Mengefisiensikan menu di setiap outlet yang ditangani oleh main kitchen. Banyaknya makanan yang ditangani disetiap restoran menyebabkan menurunnya taste pada saat penyajian oleh karena itu chef de partie di main kitchen harus mengefisienkan menu makanan yang ada agar dapat menjaga kualitas makanan.

\section{Simpulan}

Berdasarkan hasil penelitian yang telah diuraikan pada bab sebelumnya dapat ditarik beberapa kesimpulan sebagai berikut:

1. Discovery Kartika Plaza Hotel memiliki prosedur penyimpanan yang sesuai dengan sistem Hazard Analysis and Critical Control Point (HACCP), diantaranya:

a) Proses penerimaan bahan makanan di main kitchen yang akan disimpan.

b) Pengaturan suhu penyimpanan.

c) Cara-cara penyimpanan yang sesuai sistem Hazard Analysis and Critical Control Point (HACCP).

d) Penempatan dan pengambilan barang sesuai sistem FIFO (First In First Out).

e) Penggunaan tempat penyimpanan yang cukup memadai seperti thawing chiller, meat and fish freezer, vegetable chiller, dry store dan hot box.

2. Dalam melaksanakan kegiatan-kegiatan di main kitchen Discovery Kartika Plaza Hotel, banyak mengalami permasalahan, seperti:

a) Ketersediaan tempat penyimpanan bahan makanan.

b) Kelalaian terhadap sistem penyimpanan FIFO.

c) Kurangnya pengendalian bahaya pangan sesuai $H A C C P$.

3. Untuk mengatasi permasalahan yang ada chef de partie di main ktichen melakukan upaya-upaya dalam dalam mengatasi permasalahan tersebut, upaya yang dilakukan diantaranya: 
a) Penggunaan barang yang lama terlebih dahulu FIFO (first in firts out)

b) Menekankan akan bahaya pada kelalaian dalam penyimpanaan yang tidak sesuai prosedur.

c) Pemberian training tentang Hazard Analysis and Critical Control Point (HACCP) kepada setiap karyawan main kitchen

\section{DAFTAR PUSTAKA}

Anonim. Peta lokasi hotel discovery kartika plaza, Tersedia pada https://www.bing.com/maps?q=discovery+kartika+plaza\&FORM=HDRSC4 diakses pada 12 april 2019.

Annisa,Chitra.2008.Penyusunan Rencana Hazard Analysis Critical Control Points(HACCP) di PT Pangan Rahmat Buana, Sentul. Tersedia pada http://repository.ipb.ac.id/ (diakses 10 april 2019)

Bestari Monika Cindar.2018. Sanitasi dan Personal Hyegiene dalam Kitchen Hotel Louis Kienne Pandaran Semarang. Tersedia pada http://repository.unika.ac.id/17534/1/15.12.0035\%20Monika.pdf (diakses 10 April 2019)

Hadi,Wisnu. 2015. Peranan Higiene dan Sanitasi dalam Proses Pengolahan Makanan dari Hotel Brongto Yogyakarta. terseedia pada https://ejournal.bsi.ac.id/ejurnal/index.php/khasanah/article/view/527 (diakses 10 April 2019)

Hermawan, Thaheer. 2005. Sistem Manajemen HACCP (Hazard Analysis Critical Control Points). Bumi Aksara, Jakarta.

Prasetyanto Hermawan.2018. Analisis Penerapan HACCP Pada Pengolahan Makanan Di Main kitchen Hyatt Regency Yogyakarta. Tersedia pada shttps://www.google.com/url?sa=t\&rct=i\&q=\&esrc=s\&source=web\&cd=1\&c ad=rja\&uact=8\&ved=2ahUKEwjPg8C038fhAhUXY48KHdFpAN8QFiAAegQ IARAB\&url=https\%3sA\%2F\%2Fosf.io\%2Fpreprints\%2Finarxiv\%2Fhnbma \%2F\&usg=AOvVaw09Siawh5-D0xi3KIYXAovi (diakses 10 April 2019)

Pratiwi, Widya.2014. Pengaruh Penerapan Pre-requisite Program Dan Implementasi HACCP Terhadap Jaminan Keamanan Makanan di Aston Braga Hotel \& Residence. Tersedia pada http://repository.upi.edu/16277/ (diakses 10 April 2019)

Samsul Huda dan Nurcahyo. 2015. Upaya Food and Beverage Product Dalam Meningkatkan Kualitas Makanan di Hotel Grand Aston Yogyakarta. Tersedia pada https://ejournal.bsi.ac.id/ejurnal/index.php/khasanah/article/view/524/416. (di akses pada 15 Januari 2019)

Widianto Tri, Mayasari Citra Unik.2018. Penerapan Hazard Analysis And Critical Control Point Di Main Kitchen Hotel Ibis Styles Yogyakarta. Tersedia pada 
JMPP, Vol 2 No 1, April 2019

p-ISSN: 2654-9719

https://www.google.com/url?sa=t\&rct=j\&q=\&esrc=s\&source=web\&cd=1\&ca $\mathrm{d}=$ rja\&uact=8\&ved=2ahUKEwilhaCt3sfhAhWMP48KHQOhDQoQFjAAegQI BBAC\&url=https\%3A\%2F\%2Fejournal.bsi.ac.id\%2Fejurnal\%2Findex.php\% 2Fkhasanah\%2Farticle\%2Fdownload\%2F3607\%2F2363\&usg=AOvVaw3R 1rH47V5DWnQBDle07AOs (diakses 10 April 2019)

Wulandari Risni. 2017 Hygiene dan Sanitasi Untuk Meningkatkan Kualitas Kebersihan Kitchen di Loji Hotel Surakarta. tersedia pada https://eprints.uns.ac.id/39055/1/C9414046 pendahuluan.pdf (diakses 10 April 2019) 